\title{
Formation and regulation of supramolecular chirality in organogel via addition of tartaric acid
}

\author{
CAO XinHua ${ }^{1,2}$, ZHANG MingMing ${ }^{1}$, LIU KeYin ${ }^{1}$, MAO YueYuan ${ }^{1}$, LAN HaiChuang ${ }^{1}$, \\ LIU Bin ${ }^{1} \&$ YI Tao ${ }^{1 *}$ \\ ${ }^{1}$ Department of Chemistry, Fudan University, Shanghai 200433, China; \\ ${ }^{2}$ College of Chemistry and Chemical Engineering, Xinyang Normal University, Xinyang 464000, China
}

Received April 9, 2012; accepted June 12, 2012; published online September 25, 2012

\begin{abstract}
A new 1,8-naphthalimide derivative was prepared in which the C-4 position was substituted by pyridin-4-ol. This derivative shows good gelation property that can gelate most of polar solvents. As an achiral molecule, helical fibre morphology was observed when the compound gelated acetone solvent. When 0.5 eq of $D$-tartaric acid or $L$-tartaric acid was added to the gel, the helical morphology was changed from left-handed to right-handed structure. This result was further proved by circular dichroism measurement. FT-IR experiment showed the formation of intermolecular H-bond between the gelator and tartaric acid. The photophysical properties of gelator had no difference before and after addition of tartaric acid; whereas the lamellar structure was varied by addition of tartaric acid.
\end{abstract}

helical structure, intermolecular H-bond, organogel, self-assembly, tartaric acid

Citation: Cao X H, Zhang M M, Liu K Y, et al. Formation and regulation of supramolecular chirality in organogel via addition of tartaric acid. Chin Sci Bull, 2012, 57: 4272-4277, doi: 10.1007/s11434-012-5436-0

Low molecular mass organogels (LMOGs) are attractive due to their diverse application in medicine, sensors, water purification, optical-electric device, oil storage, catalysis, etc [1]. Those LMOGs are made by the fine control of the self-assembly in supramolecular systems for the desired outcome which is a challenge to chemists. Recently, chiral supramolecular assemblies have attracted widespread attention due to potential applications in enantioselective catalysis [2-4], molecular recognition [5], etc. In general, chiral components are easily assembled into chiral supramolecular systems. So far, several papers have reported chiral assembly formation from completely achiral molecules induced by certain chiral substrates [6]. But the chiral supramolecular assembly is spontaneous. The regulation of supramolecular chirality is important for chiral assembly application in material science.

Tartaric acid (TA) and its derivatives are very popular and important compounds as chiral reagents for the separation of enantiomer due to their wide variety of sources and

*Corresponding author (email: yitao@fudan.edu.cn) low cost [7]. Tartaric acid was applied to supramolecular self-assembly as a neoteric and grateful proton donor with two carboxylic acid and two hydroxyl groups of the symmetrical structure [8]. Huc et al. [9] prepared tartaric acid ramifications which could gelate organic solvents and water, assembling into twisted ribbons. Shinkai and co-workers [10] have previously reported double helical silica fibrils with the same system. In one recent example, a highly fluorescent chiral organogel with transparency was prepared via H-bonding between tartaric acid and achiral gelator containing pyridine group [11]. In this work, we sought to investigate the chiral supramolecular self-assemble from the achiral gelator molecular via addition of $D$-tartaric acid (D-TA) and $L$-tartaric acid ( $L$-TA).

\section{Experimental}

\subsection{Materials}

All starting materials were obtained from commercial 
suppliers and used as received. $D$ - and $L$-tartaric acid (97\%) were provided from Fluka. Dicyclohexylcarbodiimide (99\%) were obtained from Acros. Pyridin-4-ol (CP), ethane-1,2diamine (98.5\%), 1-bromododecane (99\%), 4-bromo-1,8naphthalic anhydride (95\%), triethylamine (AR), 1-hydroxybenzotriazole (95\%), methyl 3,4,5-trihydroxybenzoate (AR) and 6-aminohexanoic acid (AR) were supplied from Sinopharm Chemical Reagent Co., Ltd. (Shanghai). Column chromatography was carried out on silica gel (200-300 mesh).

\subsection{Synthesis}

Compounds $\mathbf{3}$ and $\mathbf{4}$ were synthesized according to the ref. [12].

Compound 5: A mixture of 4 (2.0 g, $4.95 \mathrm{mmol}), \mathrm{LiOH}$ $(8.32 \mathrm{~g}, 198 \mathrm{mmol})$ in water $(30 \mathrm{~mL})$ and THF $(30 \mathrm{~mL})$ was stirred at room temperature for $48 \mathrm{~h}$. The reaction mixture was concentrated in vacuo. The solution was acidified with concentrated hydrochloric acid to $\mathrm{pH} 2-3$. The precipitate was collected by filtration to afford $\mathbf{5}$ (yield $85.7 \%$ ) as a pale solid. M.p. $147-148^{\circ} \mathrm{C},{ }^{1} \mathrm{H}$ NMR $(400 \mathrm{MHz}$, DMSO- $\left.d_{6}\right): \delta 11.940(\mathrm{~s}, 1 \mathrm{H}), 8.477(\mathrm{~d}, 1 \mathrm{H}, J=7.6 \mathrm{~Hz})$, 8.443 (d, $1 \mathrm{H}, J=8.8 \mathrm{~Hz}), 8.236(\mathrm{~d}, 1 \mathrm{H}, J=8 \mathrm{~Hz}), 8.126$ (d, $1 \mathrm{H}, J=8 \mathrm{~Hz}), 7.921(\mathrm{t}, 1 \mathrm{H}, J=7.8 \mathrm{~Hz}), 3.957(\mathrm{t}, 2 \mathrm{H}, J=$ $7.4 \mathrm{~Hz}), 2.172$ (t, 2H, $J=7.4 \mathrm{~Hz}), 1.585(\mathrm{~m}, 2 \mathrm{H}), 1.508(\mathrm{~m}$, 2H), $1.303(\mathrm{~m}, 2 \mathrm{H}) ;{ }^{13} \mathrm{C}$ NMR (100 MHz, DMSO- $\left.d_{6}\right): \delta$ 175.0, 163.4,133.1, 132.1, 131.9, 131.5, 130.3, 131.9, 131.5, 130.3, 129.6, 129.3, 128.8, 122.5, 40.5, 34.0, 27.7, 26.5, 24.7. HRMS $\left(\mathrm{ESI}^{+}\right.$) calcd. for $\mathrm{C}_{18} \mathrm{H}_{16} \mathrm{BrNNaO}_{4}\left[\mathrm{M}+\mathrm{Na}^{+}\right]$: 412.0160 ; found: 412.0160 .

Compound 6: A mixture of 5 (1.5 g, $3.84 \mathrm{mmol}), 3$ (3.03 $\mathrm{g}, 4.22 \mathrm{mmol}$ ), dicylohexylcarbodiimide (DCC) (2.38 g, $11.52 \mathrm{mmol})$, 1-hydroxybenzotriazole (HOBt) (1.56 g, $11.52 \mathrm{mmol})$ and $\mathrm{Et}_{3} \mathrm{~N}(1.29 \mathrm{~mL}, 11.52 \mathrm{mmol})$ in anhydrous THF (50 mL) was stirred for $24 \mathrm{~h}$ under nitrogen atmosphere. The reaction mixture was concentrated in vacuo to give crude compound, which was purified by column chromatography $\left(\mathrm{SiO}_{2}\right.$ gel; $\left.\mathrm{CHCl}_{3} / \mathrm{MeOH}=50: 1, \mathrm{v} / \mathrm{v}\right)$ to give 6 $(2.5 \mathrm{~g}, 60.0 \%)$ as a pale solid. M.p. $225-226^{\circ} \mathrm{C} ;{ }^{1} \mathrm{H} \mathrm{NMR}$ $\left(400 \mathrm{MHz}, \mathrm{CDCl}_{3}\right): \delta 8.63(\mathrm{~d}, 1 \mathrm{H}, J=8 \mathrm{~Hz}), 8.58(\mathrm{~d}, 1 \mathrm{H}, J$ $=8 \mathrm{~Hz}), 8.39(\mathrm{~d}, 1 \mathrm{H}, J=8 \mathrm{~Hz}), 8.04(\mathrm{~d}, 1 \mathrm{H}, J=8 \mathrm{~Hz}), 7.84$ (t, 1H, J = 8 Hz), $7.02(\mathrm{~s}, 2 \mathrm{H}), 7.30(\mathrm{~s}, 1 \mathrm{H}), 6.43(\mathrm{~s}, 1 \mathrm{H})$, $4.12(\mathrm{t}, 2 \mathrm{H}, J=8 \mathrm{~Hz}), 4.00(\mathrm{t}, 4 \mathrm{H}, J=8 \mathrm{~Hz}), 3.95(\mathrm{t}, 2 \mathrm{H}, J$ $=8 \mathrm{~Hz}), 3.53(\mathrm{~s}, 4 \mathrm{H}), 2.25(\mathrm{t}, 2 \mathrm{H}, J=8 \mathrm{~Hz}), 1.78-1.71(\mathrm{~m}$, $10 \mathrm{H}), 1.44(\mathrm{~m}, 8 \mathrm{H}), 1.26-1.24(\mathrm{~m}, 48 \mathrm{H}), 0.87(\mathrm{t}, 9 \mathrm{H}, J=8$ $\mathrm{Hz}) .{ }^{13} \mathrm{C} \mathrm{NMR}\left(100 \mathrm{MHz}, \mathrm{CDCl}_{3}\right): \delta 174.9,168.1,163.7$, $153.1,140.9,133.4,132.1,131.3,131.2,130.7,130.4$, $129.0,128.8,128.2,123.0,122.2,105.5,73.5,69.2,41.7$, 40.2 , 39.8, 36.4, 32.0, 30.4, 29.8, 29.5, 27.6, 26.5, 26.2, 25.2, 22.8, 14.2. HRMS (ESI ${ }^{+}$) calcd. for $\mathrm{C}_{63} \mathrm{H}_{98} \mathrm{BrN}_{3} \mathrm{NaO}_{7}$ $\left[\mathrm{M}+\mathrm{Na}^{+}\right]$: 1110.6486 ; found: 1110.6476 .

Target compound 1: 6 (1.5 g, $1.37 \mathrm{mmol})$, pyridin-4-ol $(0.29 \mathrm{~g}, 3.03 \mathrm{mmol})$ and $\mathrm{K}_{2} \mathrm{CO}_{3}(0.57 \mathrm{~g}, 4.13 \mathrm{mmol})$ were mixed in DMF $(30 \mathrm{~mL})$. The reaction mixture was stirred for $3 \mathrm{~h}$ under a nitrogen atmosphere at $100^{\circ} \mathrm{C}$. Then the solvent was removed under reduced pressure and the residue was subjected to column chromatography $\left(\mathrm{CH}_{2} \mathrm{Cl}_{2}-\mathrm{MeOH}\right.$ : $50 / 1, \mathrm{v} / \mathrm{v}$ ) on silica gel to give $\mathbf{1}$ as a white powder. M.p. $143-145{ }^{\circ} \mathrm{C} ;{ }^{1} \mathrm{H}$ NMR (400 MHz, $\mathrm{CDCl}_{3}$ ): $\delta 8.654$ (d, $1 \mathrm{H}, J=8 \mathrm{~Hz}), 8.610(\mathrm{~d}, 1 \mathrm{H}, J=8 \mathrm{~Hz}), 7.986(\mathrm{~d}, 1 \mathrm{H}, J=8.4$ $\mathrm{Hz}), 7.860$ (t, 1H, $J=7.8 \mathrm{~Hz}), 7.732(\mathrm{~d}, 1 \mathrm{H}, J=7.6 \mathrm{~Hz})$, 7.644 (d, 2H, J = 7.2), 7.344 (s, 1H), 6.947 (s, 2H), 6.655 (d, $2 \mathrm{H}, J=6.8 \mathrm{~Hz}), 6.485(\mathrm{~s}, 1 \mathrm{H}), 4.172(\mathrm{t}, 2 \mathrm{H}, J=7.2 \mathrm{~Hz})$, $3.983(\mathrm{~m}, 6 \mathrm{H}), 3.521(\mathrm{~s}, 4 \mathrm{H}), 2.274(\mathrm{t}, 2 \mathrm{H}, J=7.2$ $\mathrm{Hz}), 1.796$ ( $\mathrm{m}, 10 \mathrm{H}), 1.467$ (m, 8H), 1.272 (m, 48H), 0.893 $(\mathrm{m}, 9 \mathrm{H}, J=6.6 \mathrm{~Hz}) .{ }^{13} \mathrm{C} \mathrm{NMR}\left(100 \mathrm{MHz}, \mathrm{CDCl}_{3}\right): \delta 174.8$, $167.9,163.5,163.0,152.9,143.9,141.1,140.6,132.4$, $131.0,129.1,128.8,127.9,127.6,127.1,124.7,123.5$, $123.4,118.8,105.2,73.5,69.1,41.8,40.5,39.9,36.3,32.0$, $30.4,29.8,29.5,27.7,26.5,26.2,25.2,22.8,14.2$. HRMS (ESI+) calcd for $\mathrm{C}_{68} \mathrm{H}_{102} \mathrm{~N}_{4} \mathrm{NaO}_{8}\left[\mathrm{M}+\mathrm{Na}^{+}\right]$: 1125.7595 ; found: 1125.7591 .

\subsection{Characterization and measurements}

The ${ }^{1} \mathrm{H}$ NMR (400 MHz) and ${ }^{13} \mathrm{C}$ NMR (100 MHz) spectra were recorded on a Mercury plus-Varian instrument. Proton chemical shifts are reported in parts per million downfield from tetramethylsilane (TMS). HRMS was obtained on LTQ-Orbitrap mass spectrometer (ThermoFIsher, San Jose, CA). Fourier transform infrared (FT-IR) spectra were collected by a Nexus 470 spectrometer (Nicolet Company), powder samples were prepared with $\mathrm{KBr}$ pellets, gel
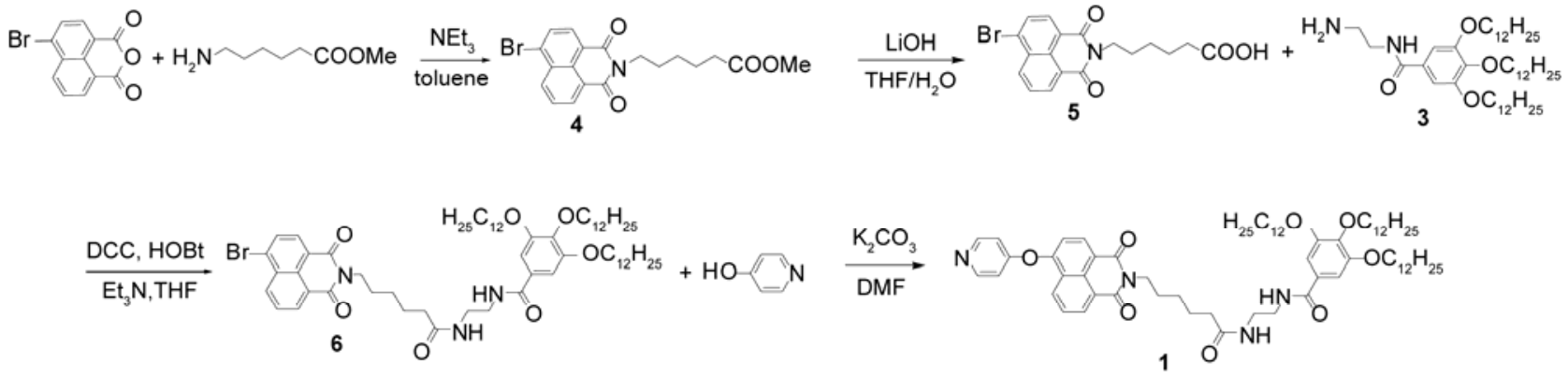

Scheme 1 The synthesis route of the target compound 1. 
samples were measured by using a $\mathrm{KBr}$ cell. FE-SEM images were obtained using a FE-SEM S-4800 instrument (Hitachi). Samples were prepared by spinning the samples on glass slices and coating with Au. TEM was performed on a JEOL JEM2011 apparatus operating at $200 \mathrm{kV}$. The samples were prepared by coating the diluted wet gels on a copper grid at room temperature and freeze drying for $24 \mathrm{~h}$. Powder X-ray diffractions were generated by using a Philips PW3830. X-ray generator (Cu target, $\lambda=0.1542 \mathrm{~nm}$ ) with a power of $40 \mathrm{kV}$ and $40 \mathrm{~mA}$ was used. UV-Vis absorption spectra were recorded on a UV-Vis 2550 spectroscope (Shimadzu). Fluorescent spectra were recorded on an Edinburgh Instruments FLS 900. CD (circular dichroism) spectra were recorded on a MOS-450 spectropolarimeter.

\subsection{Gelation test for organic fluids}

The gelators and solvents were put in a septum-capped test tube and heated $\left(>75^{\circ} \mathrm{C}\right)$ until the solid was dissolved. The sample vial was then cooled to $25^{\circ} \mathrm{C}$ (room temperature). Qualitatively, gelation was considered successful if no sample flow was observed upon inversion of the container at room temperature (the inverse flow method).

\section{Results and discussion}

The gelation ability of compound $\mathbf{1}$ was assessed by dissolving the compound with the concentration of $25 \mathrm{mg} \mathrm{mL}^{-1}$ in a variety of solvents, as shown in Table 1 . Compound $\mathbf{1}$ could form gels in most of the polar solvents, such as DMSO, DMF, 1,4-dioxane, acetonitrile, acetone and methanol with the moderate concentration of $25 \mathrm{mg} \mathrm{mL}^{-1}$. The compound $\mathbf{1}$ could not gelate ethanol and form a solution at the same concentration. The hydrogel of compound $\mathbf{1}$ was not obtained due to the too low solubility in water. But the ethanol solution of $\mathbf{1}$ was changed into a gel after addition of isovolumetric water. When $D$-TA or $L$-TA was added to the above gel, a two-component gel formed in the solvents listed in Table 1. The solution of compound $\mathbf{1}$ in ethanol also formed gel after addition of tartaric acid. Herein, we studied the detailed properties of gels including $1,1+0.5$ eq $D$-TA, $1+0.5$ eq $L$-TA in acetone.

In order to obtain a visual insight into the molecular aggregation mode in the gel specimens, the morphologies of the xerogels were analyzed by field emission scanning electron microscopy (FE-SEM) after drying and coating with $\mathrm{Au}$. The SEM image of xerogel $\mathbf{1}$ from acetone showed the characteristic entangled threadlike morphology with a width of around $100 \mathrm{~nm}$ (Figure 1(a)). When the same sample was observed by TEM, a right-handed helical twist in the xerogel fibres was seen in Figure 1( $\left.\mathrm{a}^{\prime}\right)$. In fact, the compound 1 was an achiral molecule. Yuan et al. [13] and Zhang et al. [14] had reported chiral molecular assemblies from achiral amphiphilic imidazole-based ligand with $\mathrm{AgNO}_{3}$ in gel state
Table 1 Gelation properties of $\mathbf{1}$ in a variety of polar solvents ${ }^{\text {a) }}$

\begin{tabular}{|c|c|c|c|}
\hline Solvent & 1 & $1+D-\mathrm{TA}^{\mathrm{b})}$ & $1+L-\mathrm{TA}^{\mathrm{b})}$ \\
\hline DMSO & G (25) & G (25) & G (25) \\
\hline DMF & $\mathrm{G}(25)$ & $\mathrm{G}(25)$ & $\mathrm{G}(25)$ \\
\hline 1,4-Dioxane & $\mathrm{G}(25)$ & $\mathrm{G}(25)$ & G (25) \\
\hline Acetonitrile & G (25) & G (25) & $\mathrm{G}(25)$ \\
\hline Ethanol & S & $\mathrm{G}(25)$ & G (25) \\
\hline Methanol & G (25) & G (25) & $G(25)$ \\
\hline $\mathrm{H}_{2} \mathrm{O}$ & NS & NS & NS \\
\hline Acetone & G (25) & $\mathrm{G}(25)$ & G (25) \\
\hline $\begin{array}{c}\text { Ethanol/ } \mathrm{H}_{2} \mathrm{O} \\
(1 / 1, \mathrm{v} / \mathrm{v})\end{array}$ & $\mathrm{G}(12.5)$ & $\mathrm{G}(12.5)$ & G (12.5) \\
\hline
\end{tabular}

a) Heated to dissolve and cooled to room temperature then aged for 15 $\min \left(25^{\circ} \mathrm{C}\right)$. b) The amount of tartaric acid was 0.5 eq of $\mathbf{1}$. G: gel; S: solution; NS: not soluble. The critical gelation concentrations of the gelators are given in parentheses $\left(\mathrm{mg} \mathrm{mL}^{-1}\right)$

and LB films, respectively. The helical structure obtained from the achiral molecule was possible an occurrence of statistical fluctuations in the intermolecular self-assembly process, which could lead to an accidental excess of one helical direction [15-18]. After one helical direction was formed, the new aggregates would follow to form a helical secondary structure along with the same direction by chiral autocatalysis [14]. This helical structure self-assembled by achiral molecules was usually accompanied by chance. Herein, a chiral molecule was added to the system and the achiral molecule self-assembly was controlled and tuned. The two-component gels obtained through addition of 0.5 eq of $D$-TA and $L$-TA to 1 was investigated by FE-SEM. The morphology of the xerogel of $\mathbf{1}+0.5 D$-TA was also entangled fibers on the whole (Figure 1(b)). TEM image of a single fiber revealed that the structure was changed from right-handed to left-handed helical structure (Figure 1( $\left.\mathrm{b}^{\prime}\right)$ ). This result indicated that the $D$-TA was a chiral center with which the molecular aggregation was followed. When 0.5 eq of $L$-TA was added, the morphology was similar to the gel 1 and still kept the right-handed helical structure (Figure $1(\mathrm{c})$ and $\left.\left(\mathrm{c}^{\prime}\right)\right)$. The analysis of these micro- or nanostructure revealed that the tartaric acid can guide and tune the chiral aggregation of molecule 1. Simultaneous, the gelation ability was not affected.

The "supramolecular chirality" obtained by molecular aggregation behavior was further studied by circular dichroism (CD) spectra. In the absence of tartaric acid, a weak negative and broad band at $400 \mathrm{~nm}$ in the CD spectrum of the gel 1 indicated a helical conformation in the sol-gel process in Figure 2. The negative peak at $400 \mathrm{~nm}$ might correspond to the molecular self-assembly induced chirality on the naphthalimide group $[19,20]$. When 0.5 eq of $L$-TA was added to gel $\mathbf{1}$, the negative band at $400 \mathrm{~nm}$ was obviously strengthened, indicating that $L$-TA was able to enhance chirality in compound 1 . When 0.5 eq of $D$-TA was added, the band at $400 \mathrm{~nm}$ was changed from negative to positive, which suggested that the supramolecular chirality of compound $\mathbf{1}$ was determined by $D$-TA. This result showed that tartaric acid acted as a chiral center for promoting compound $\mathbf{1}$ self- 


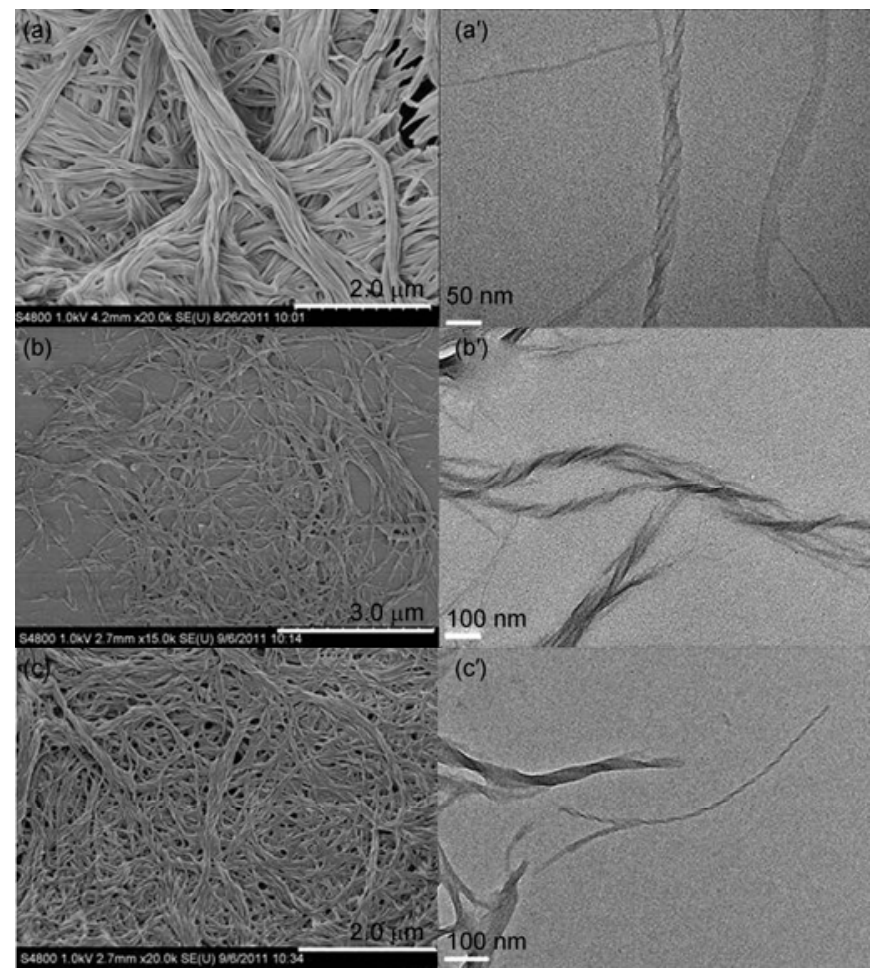

Figure 1 SEM ((a), (b), (c)) and TEM $\left(\left(a^{\prime}\right),\left(b^{\prime}\right),\left(c^{\prime}\right)\right)$ images of the xerogels obtained from acetone at room temperature (25 $\left.5^{\circ}\right)$; (a) and (a') for gel 1, (b) and (b') for gel 1+0.5 eq $D$-TA, c and c' for gel 1+0.5 eq $L$-TA. The scale bars for (a), (a'), (b), (b'), (c) and (c') are $2 \mu \mathrm{m}, 50 \mathrm{~nm}, 3 \mu \mathrm{m}, 100 \mathrm{~nm}, 2 \mu \mathrm{m}, 100 \mathrm{~nm}, \mathrm{re}-$ spectively. The concentrations of the gels are all $25 \mathrm{mg} \mathrm{mL}^{-1}$.

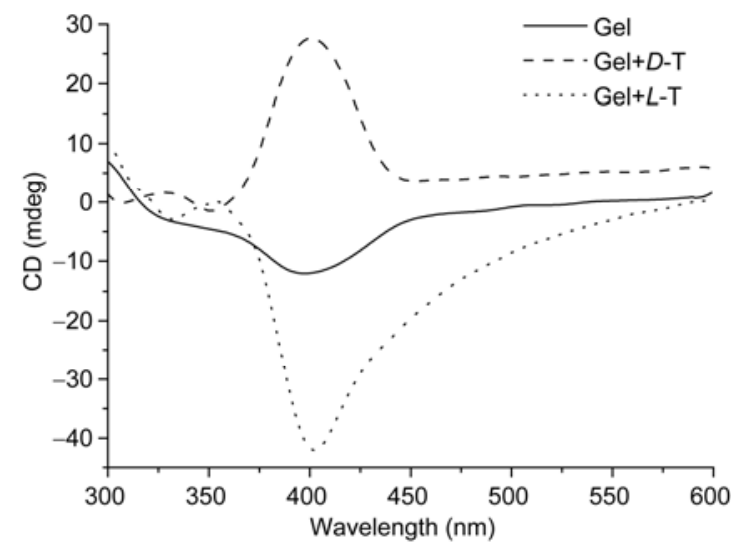

Figure 2 CD spectra of gel 1, gel $1+0.5$ eq $D$-TA, gel 1+0.5 eq $L$-TA in acetone $\left(C_{\mathrm{gel}}=25 \mathrm{mg} \mathrm{mL}^{-1}\right)$.

assembly to a certain direction through intermolecular hydrogen-bond. Thus, control over the absolute helix handedness of compound $\mathbf{1}$ in the self-assembly process was achieved by addition of pure $D$ - or $L$-TA.

The FT-IR investigation was performed in order to ascertain how the interaction of the compound $\mathbf{1}$ and tartaric acid in Figure 3. The two peaks at 3338 and $1740 \mathrm{~cm}^{-1}$ were assigned to the absorption of $\mathrm{OH}$ and $\mathrm{C}=\mathrm{O}$ of the tartaric acid carboxyl group [21]. After the tartaric acid was added to the gel 1 system, the above two peaks were disappeared. This result was side proved that tartaric acid interaction

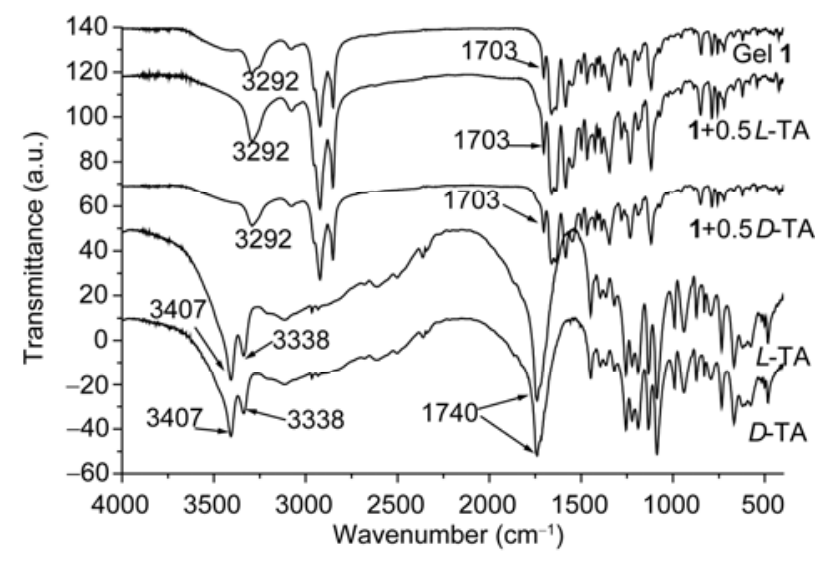

Figure 3 FT-IR spectra of tartaric acid, the xerogel 1, xergel of $1+0.5$ eq $D$-TA, xergel of $\mathbf{1}+0.5$ eq $L$-TA under room temperature.

with $\mathbf{1}$ and the intermolecular H-bond formation.

The UV-Vis absorption spectra and fluorescence emission spectra were also carried out for further understanding the molecular self-assembly behavior in gel state. Acetone has a strong absorption in ultraviolet band, so acetonitrile was selected as solvent in these experiments. The concentration-dependent UV-Vis absorption spectra were showed in Figure 4(a). The absorption spectrum of the compound $\mathbf{1}$ in acetonitrile solution showed a series of peaks at 213, 237, $263,350 \mathrm{~nm}$. The absorption peaks had not any shift with the solution concentration increasing from $10^{-6}$ to $10^{-4}$ 

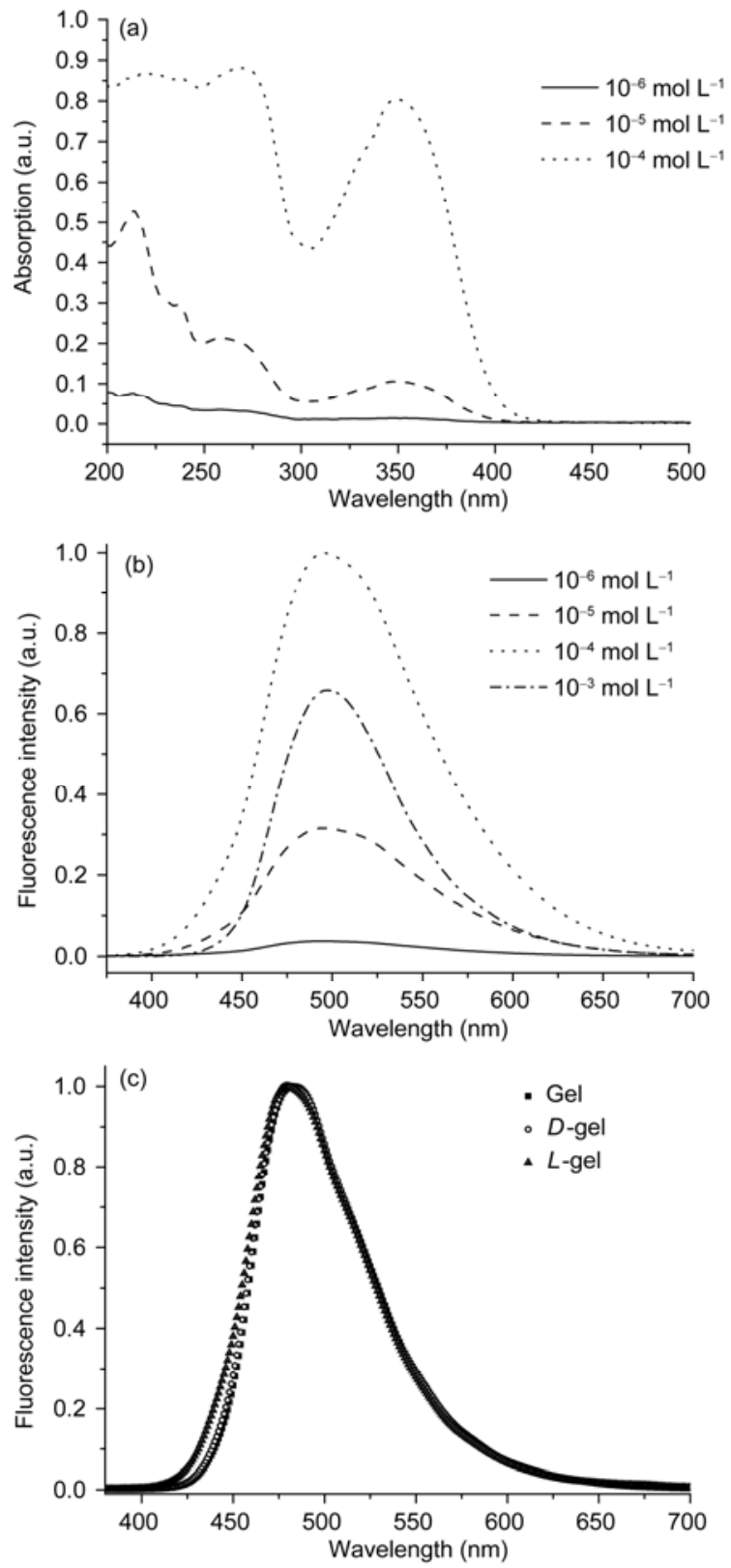

Figure 4 (a) Concentration dependent UV-Vis spectra; (b) concentration dependent fluorescence emission spectra of compound $\mathbf{1}$ in acetonitrile ( cell length $=1 \mathrm{~cm}, \lambda_{\mathrm{ex}}=356 \mathrm{~nm}$ ); (c) the fluorescence emission of spectra of gel 1 , gel $1+0.5$ eq $D$-TA and gel $1+0.5$ eq $L$-TA $\left(C_{\text {gel }}=25 \mathrm{mg} \mathrm{mL}^{-1}, \lambda_{\text {ex }}\right.$ $=356 \mathrm{~nm})$.

mol L ${ }^{-1}$. The fluorescence emission band at $495 \mathrm{~nm}$ also had no shift with the solution concentration increasing in Figure 4(b). When the concentration was up to $10^{-3} \mathrm{~mol} \mathrm{~L}^{-1}$, the emission intensity was obviously weakened. This indicated that there is no obvious $\pi-\pi$ interaction between molecules of $\mathbf{1}$. When $0.5 \mathrm{eq}$ of tartaric acid was added to gel $\mathbf{1}$, the emission band had no shift, indicating that the tartaric acid did not affect the optical properties of $\mathbf{1}$ (Figure 4(c)).

The molecular packing of $\mathbf{1}$ in the xerogel state before and after addition of tartaric acid was further investigated

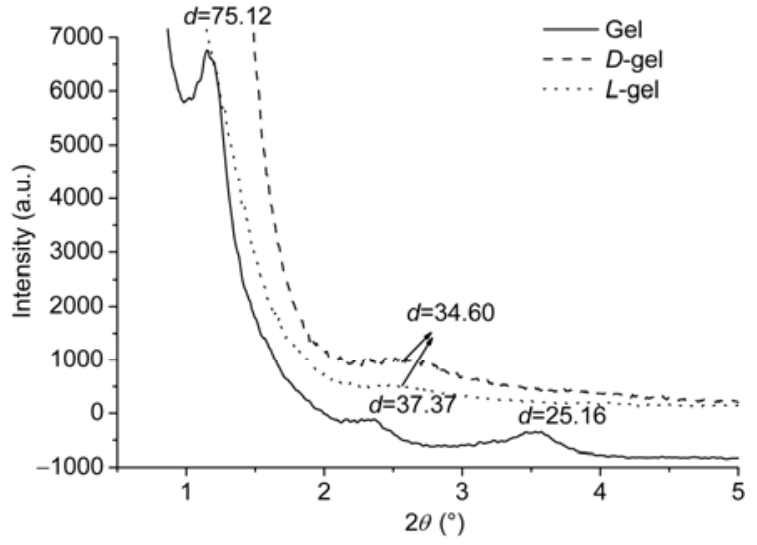

Figure 5 XRD patterns of xerogel 1, $1+0.5$ eq $D$-TA, $1+0.5$ eq $L$-TA.

by powder X-ray diffraction in Figure 5. The scattering patterns of 1 xerogel showed a series of diffraction peaks at $2 \theta=1.18^{\circ}, 2.35^{\circ}, 3.52^{\circ}$ with the corresponding to $d$ spacing values of $75.1,37.4,25.1 \AA(d / 1, d / 2, d / 3)$ [22-24], which strongly suggested a lamellar structure. After addition of 0.5 eq $D$-TA or $L$-TA, the series of peaks disappeared and a new peak at $2 \theta=2.59^{\circ}$ with the corresponding $d$ spacing value of $34.6 \AA$ was emerged, which indicated the lamellar structure was changed.

\section{Conclusions}

In summary, a novel achiral 1,8-naphthalimide-based gelator was designed and found to form helical fibre morphology through gelation in a wide range of polar solvents at room temperature. The helical morphology was found to be tuned by addition of tartaric acid through formation intermolecular H-bond. The fluorescence emission of gel was not affected by addition of tartaric acid. The lamellar structure of gel was changed after addition of tartaric acid. This work may open an easy way of constructing helical nanostructure via non-covalent interactions.

This work was supported by the National Science Fund for Distinguished Young Scholars (21125104), the Major Research Plan of the National Natural Science Foundation of China (91022021), the National Basic Research Program of China (2009CB930400), the Program for Innovative Research Team in University (IRT1117), and Shanghai Leading Academic Discipline Project (B108).

1 Sangeetha N M, Maitra U. Supramolecular gels: Functions and uses. Chem Soc Rev, 2005, 34: 821-836

2 Roelfes G, Feringa B L. DNA-based asymmetric catalysis. Angew Chem Int Ed, 2005, 44: 3230-3232

3 Boersma A J, Coquière D, Geerdink D, et al. Catalytic enantioselective syn hydration of enones in water using a DNA-based catalyst. Nat Chem, 2010, 2: 991-995

4 Wang J, Feringa B L. Control of reaction enantioselcetivity with a molecular motor switch. Science, 2011, 331: 1429-1432

5 Kuhnle A, Linderoth T R, Hammer B, et al. Chiral recognition in 
dimerization of adsorbed cysteine observed by scanning tunneling microscopy. Nature, 2002, 415: 891-893

6 Zhang L, Yuan J, Liu M H. Supramolecular chirality of achiral TPPS complexed with chiral molecular films. J Phys Chem B, 2003, 107: $12768-12773$

7 Hajmowicz H, Wisialski J, Synoradzki L. Direct hydrolysis of O-O'-dibenzoyltartaric Anhydride-An alternative method for manufacture of the same acid: Tartaric acid and its O-acyl derivatives. Part 9. Org Process Res Dev, 2011, 15: 427-434

8 Bao C Y, Lu R, Jin M, et al. $L$-tartaric assisted binary organogel system: Strongly enhanced fluorescence induced by sypramolecular assembly. Org Biomol Chem, 2005, 3: 2508-2512

9 Oda R, Huc I, Candau S J. Gemini surfactants as new, low molecular weight gelators of organic solvents and water. Angew Chem Int Ed, 1998, 37: 2689-2691

10 Sugiyasu K, Tamaru S, Takeuchi M, et al. Double helical silica fibrils by sol-gel transcription of chiral aggregates of gemini surfactants. Chem Commun, 2002, 11: 1212-1213

11 Seo J W, Chung J W, Jo E H, et al. Highly fluorescent supramolecular gels with chirality transcription through hydrogen bonding. Chem Commun, 2008, 24: 2794-2796

12 Cao X H, Wu Y Q, Liu K Y, et al. Iridium complex triggered white-light-emitting gel and its response to cysteine. J Mater Chem, 2012, 22: 2650-2657

13 Yuan J, Liu M H. Chiral molecular assemblies from anovel achiral amphihoilic 2-(heptadecyl) naphtha[2,3]imidazole through interfacial coordination. J Am Chem Soc, 2003, 125: 5051-5056

14 Zhang S Y, Yang S Y, Lan J B, et al. Helical nonracemic tubular coordination polymer gelators from simple achiral molecules. Chem Commun, 2008, 46: 6170-6172

15 Schwartz D K, Viswanathan R, Zasadzinski J A N. Commensurate defect superstructures in a Langmuir-Blodgett film. Phys Rev Lett, 1993, 70: 1267-1270

16 Qiu X, Ruiz-Garcia J, Stine K J, et al. Direct observation of domain structure in condensed monolayer phases. Phys Rev Lett, 1991, 67: 703-706

17 Tanaka S, Shirakawa M, Kaneko K, et al. Porphyrin-based organogels: Control of the aggregation mode by a pyridine-carboxylic acid interaction. Langmuir, 2005, 21: 2163-2172

18 Ishi-i T, Iguchi R, Snip E, et al. [60] Fullerene can reinforce the organogel structure of porphyrin-appended cholesterol derivatives: Novel odd-even effect of the $\left(\mathrm{CH}_{2}\right)_{n}$ spacer on the organogel stability. Langmuir, 2001, 17: 5825-5833

19 Yu X D, Cao X H, Chen L M, et al. Thixotropic and self-healing triggered reversible rheology switching in a peptide-based organogel with a cross-linked nano-ring pattern. Soft Matter, 2012, 8: 3329-3334

20 Sugiyasu K, Fujita N, Shinkai S. Visible-light-harvesting organogel composed of cholesterol-based perylene derivatives. Angew Chem Int Ed, 2004, 43: 1229-1233

21 Gao J M, Liu W T, Li M L, et al. Preparation and structural elucidation of (-)-tetrahydroberberine-(+)-2,3-di( $p$-toluyl) tartaric acid complex, J Mol Struct, 2008, 892: 466-469

22 Jung $\mathbf{J}$ H, Kobayashi $\mathrm{H}$, Masuda $\mathrm{M}$, et al. Helical ribbon aggregate composed of a crown-appended cholesterol derivative which acts as an amphiphilic gelator of organic solvents and as a template for chiral silica transcription. J Am Chem Soc, 2001, 123: 8785-8789

23 Estroff L A, Leiserowitz L, Addadi L, et al. Characterization of an organic hydrogel: A cryo-transmission electron microscopy and X-ray diffraction study. Adv Mater, 2003, 15: 38-42

24 Hanabusa K, Matsumoto M, Kimura M, et al. Low molecular weight gelators for organic fluids: Gelation using a family of cyclo (dipeptide)s. J Colloid Interface Sci, 2000, 224: 231-244

Open Access This article is distributed under the terms of the Creative Commons Attribution License which permits any use, distribution, and reproduction in any medium, provided the original author(s) and source are credited. 